\title{
INCIDÊNCIA DE GOLS RESULTANTES DE CONTRA-ATAQUES DE EQUIPES DE FUTSAL
}

Rogério V. Marchi, Faculdade de Educação Física - VERIS/IBTA/METROCAMP, Campinas, São Paulo Brasil

Carlos E. O Silva, Faculdade de Educação Física - VERIS/IBTA/METROCAMP, Campinas, São Paulo Brasil

Luis R. R. Scramin, Faculdade de Educação Física - VERIS/IBTA/METROCAMP, Campinas, São Paulo Brasil

Augusto A. Teixeira, Faculdade de Educação Física - VERIS/IBTA/METROCAMP, Campinas, São Paulo Brasil

João G. C. Chiminazzo, Faculdade de Educação Física - VERIS/IBTA/METROCAMP, Campinas, São

Paulo - Brasil

\section{RESUMO}

O objetivo deste estudo foi analisar a incidência de gols resultantes de contra-ataques em jogos de futsal de alto rendimento e observar como eles foram realizados de acordo com a sua origem e progressão até a finalização. Foi observada uma amostra de 20 jogos da Liga Nacional de Futsal de 2009, gravados em fita VHS, utilizando a observação indireta extensiva mediante formulário. Para análise dos resultados usou-se o método descritivo percentual, percebendo-se que os contra-ataques têm considerável participação nos gols marcados pelas equipes, uma vez que de um total de 88 jogos, 30 tiveram origem nas ações de contra-ataque. Porém, como se trata de uma das ações mais presentes no futsal, o número de contra-ataques não convertidos em gols é bastante maior que os convertidos visto que , a partir da coleta de dados, a conversão em gols foi de apenas $10,5 \%$ e os $89,5 \%$ restantes não resultaram em gols após a finalização da jogada, já que das 285 jogadas de contra-ataques presentes nos 20 jogos, 255 não foram convertidas em gol. A partir deste estudo percebeu-se que o contra-ataque é uma ferramenta técnico/tática no futsal sendo fator de relevância na determinação dos resultados, porém ainda deve ser melhor trabalhada para ter a sua eficiência aprimorada. Assim resultará em maior número de finalizações convertidas em gol, tornando-as eficientes em todos os aspectos e evidenciando-as como diferencial para as equipes que saibam aproveitá-las.

Palavras-Chave: Futsal; Contra-ataque; Incidência de gols.

\section{IMPACT OF GOALS RESULTING FROM THE COUNTER-ATTACK OF FUTSAL TEAM}

\begin{abstract}
The aim of this study was to analyze the incidence of goals resulting from counter-attacks in games of futsal and observe how they were carried out according to their origin and progression to completion. We observed a sample of 20 games in the National League Futsal, 2009, recorded on VHS tape, using the indirect observation through extensive form. To analyze the results used to rate the descriptive method, noting that the counter-attacks have considerable involvement in goals scored by the teams, since a total of 88 games, 30 have originated in the actions of counterattack. However, as this is an cation more present in futsal, the number of counterattacks were not converted into goals is far greater than the converted since, from the data collection, conversion into goals was only $10.5 \%$ and the remaining $89,5 \%$ did not result in goals after completation of the move, as it moves from 285 to counter-attacks present in 20 Conexões: revista da Faculdade de Educação Física da UNICAMP, Campinas, v. 8, n. 3, p. 16-22, set./dez. 2010.

ISSN: 1983-9030
\end{abstract}


games, 255 have not been converted into goal. From this study it was noticed that the counterattack is a technical tool / tactic futsal being relevant factor in determining the results, but should still be better crafted to have its efficiency improved. So will result in more completions converted into goal, making them efficient in all respects, and highlighting them as a differential for teams who can take advantage of them.

KEY-WORDS: Futsal; Counter-attack; Incidence of goals. 


\section{INTRODUÇÃO}

O futsal é uma modalidade extremamente dinâmica em que os atletas estão em constante movimentação dentro de quadra, seja atacando (com a posse de bola) ou defendendo (sem a posse de bola). Isso evidencia que além de muita velocidade e aptidão física, a versatilidade é fundamental para o atleta, ou seja, ele deve estar apto para atacar e para defender da mesma maneira e com a mesma eficiência.

Segundo Garganta, ${ }^{1}$ o esporte que se manifesta sob permanente confronto entre duas equipes exige que os jogadores atuem em conjunto para atacar e para defender e, como um jogo esportivo coletivo, exibe algumas características comuns a outras modalidades também assim classificadas, como imprevisibilidade, variabilidade de ações e comportamentos, oposição e cooperação, entre outras. Assim sendo, a prática da modalidade no alto rendimento faz com que se busquem diferenciais, fatores que determinem uma partida.

No futsal a posse de bola, a movimentação e o bom passe são essenciais para fugir da marcação adversária e conseguir um bom ataque, chegando à finalização livre de marcação e de forma equilibrada, obtendo maior chance de alcançar o objetivo principal, o gol.

Uma grande quantidade de gols é resultante de contra-ataques. Dessa forma o contra-ataque é um elemento técnico-tático de caráter ofensivo, que consiste na saída rápida da defesa para o ataque, com a finalidade de surpreender o adversário. Podendo ser de forma direta, quando o goleiro faz uma defesa e repõe rapidamente a bola a um jogador de linha que progride até concluir a gol e, quando o jogador que recuperou a bola vai à direção do gol adversário e faz a conclusão (chute no gol). Ou indireto, quando houver, após a roubada de bola, troca de passes entre os jogadores da mesma equipe antes da conclusão a gol. ${ }^{2}$

Ferreira $^{3}$ estudou em que circunstâncias as três seleções mais bem colocadas (Ucrânia, Rússia e Brasil) do Campeonato Mundial de Futsal Universitário de 1998 finalizaram a gol. O autor observou nove jogos (três de cada seleção) e descobriu que de um total de 277 ações, 38,26\% aconteceram em situação de contra-ataque. Por tudo isso que as equipe de alto rendimento têm como objetivo muitas vezes induzir o adversário a oferecer essa possibilidade de contra-atacar. Santana e Garcia, ${ }^{4}$ estudando a incidência de contra-ataque em jogos de futsal de alto rendimento, analisaram 28 jogos do Campeonato Paulista de 2003, e verificou que em um total de 521 contra-ataques, $78 \%$ foram individuais, ora precedidos da interceptação de passe, ora do 
desarme; $28,22 \%$ foram assistidos, ora por jogador de linha, ora pelo goleiro, concluindo que o contra-ataque acontece individual e coletivamente.

Partindo dessas razões, o objetivo deste estudo foi analisar a incidência de gols resultantes de contra-ataques em jogos de futsal de alto rendimento. Como objetivo secundário, pretende-se verificar como foram esses contra-ataques, de acordo com a classificação de Voser, $^{2}$ ou seja, contra-ataques de caráter direto ou indireto.

\section{MATERIAL E MÉTODO}

\section{Amostra}

Foram analisados aleatoriamente 20 (vinte) jogos de equipes participantes da Liga Nacional de Futsal de 2009.

\section{Materiais e Procedimentos}

Os jogos foram gravados em fita VHS para posterior análise e quantificação dos dados. O formulário foi desenvolvido para a coleta de incidência dos gols durante as ações de contraataques e para que se dividam os gols mediante a classificação do contra-ataque, sendo possível analisar os resultados de forma descritiva e percentual.

\section{Análise Estatística}

Para esse estudo foi realizada análise estatística utilizando Correlação de Pearson do programa Microsoft Office Excel 2003.

\section{RESULTADOS E DISCUSSÃO}

A tabela 1 expressa os resultados obtidos através dos 20 (vinte) jogos analisados da Liga Nacional de Futsal de 2009, abordando o número de ações de contra-ataques realizadas nas partidas, dividas pelas suas classificações e também totalizadas, com a demonstração do número de gols conquistados e o número de contra-ataques que não foram convertidos em gol. 
Tabela 1: Total de ações de contra-ataques convertidas ou não em gols

\begin{tabular}{lr}
\hline \multicolumn{1}{c}{ AÇÕES } & QUANTIDADES (Nº) \\
\hline Total de contra-ataques & 285 \\
Total de gols nas partidas & 88 \\
Total de gols de contra-ataques & 30 \\
Contra-ataques não convertidos em gol & 255 \\
Contra-ataques diretos & 103 \\
Contra-ataques diretos convertidos em gol & 11 \\
Contra-ataques diretos não convertidos em gol & 92 \\
Contra-ataques indiretos & 182 \\
Contra-ataques indiretos convertidos em gol & 19 \\
Contra-ataques indiretos não convertidos em gol & 163 \\
\hline
\end{tabular}

Foram totalizados 285 contra-ataques, obtendo uma média de 14,47 $( \pm 3,791)$ contra-ataques por partida. Nessas partidas foram contabilizados 88 gols, sendo 30 deles convertidos a partir de jogadas de contra-ataque, restando um total de 255 contra-ataques não convertidos em gol. Assim, percebe-se que apenas 10,5\% do total de contra-ataques são convertidos em gols (gráfico 1). Isso demonstra que é baixo o índice de gols convertidos a partir de contra-ataques.

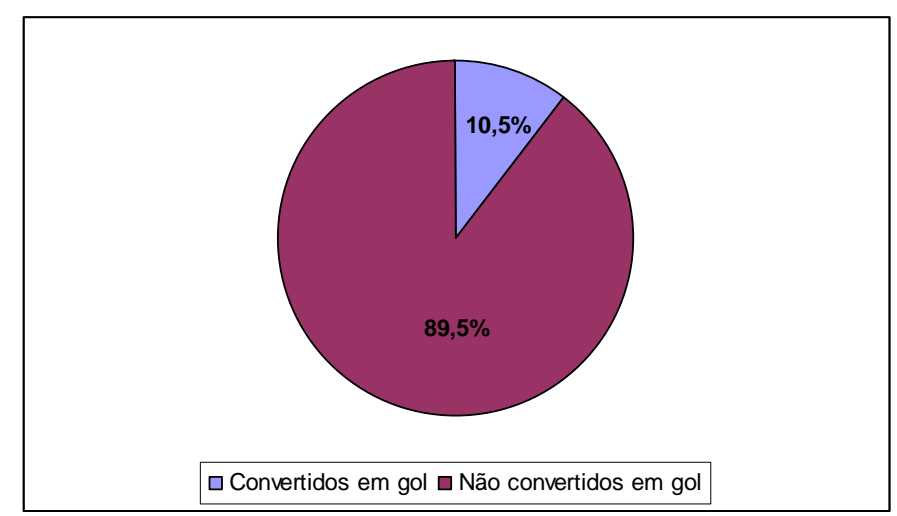

Gráfico 1: Contra-ataques convertidos ou não em gols.

Em relação à quantidade total de gols, 34,1\% dos gols são originados de contra-ataques, conforme indica o gráfico 2. 


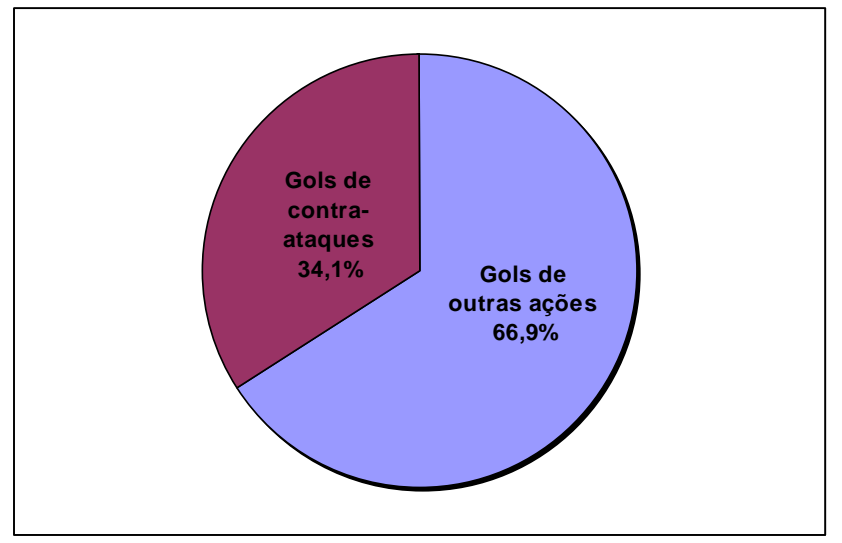

Gráfico 2: Incidência de gols de contra-ataques nos 20 (vinte) jogos.

Do total de 285 contra-ataques registrados nas partidas, 103 foram contra-ataques diretos e 182 contra-ataques indiretos. Dos 103 contra-ataques diretos, 11 (10,7\%) foram convertidos em gol e $92(89,3 \%)$ não terminaram com a realização do gol alcançado (gráfico 3).

Já os 182 contra-ataques indiretos, $19(10,4 \%)$ foram convertidos em gol e $163(89,6 \%)$ não obtiveram a realização do gol (gráfico 3).

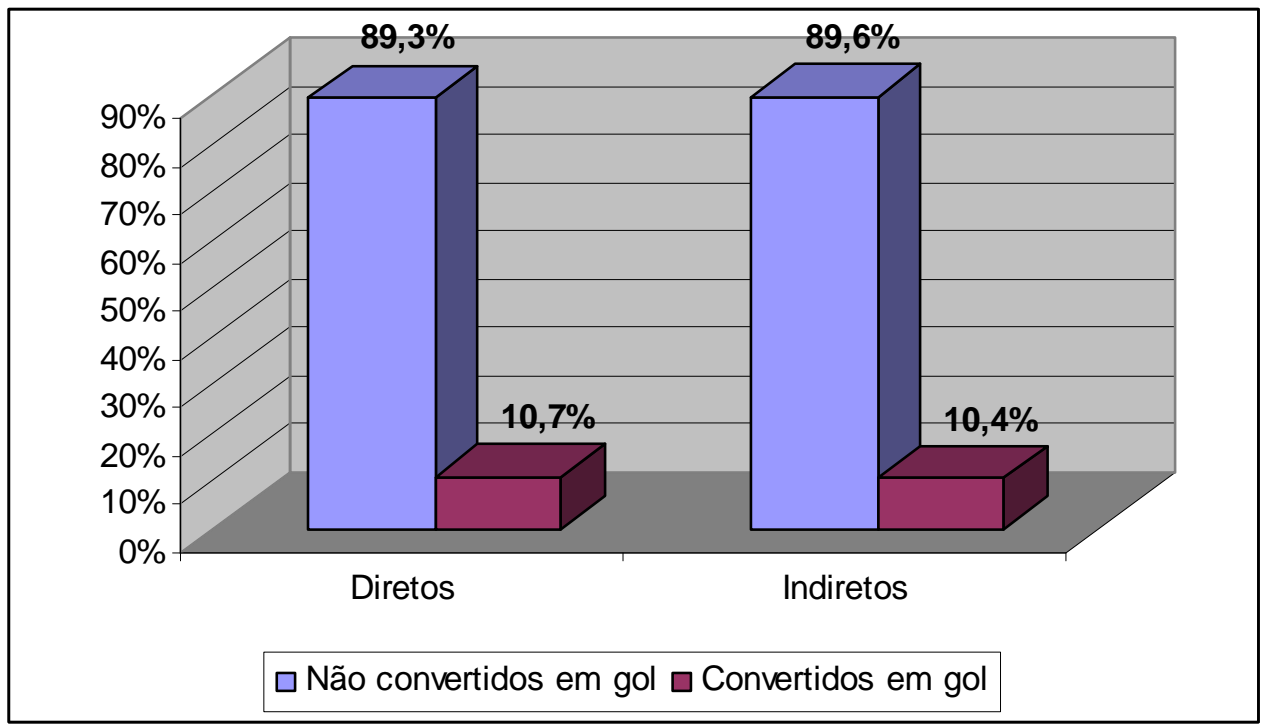

Gráfico 3: Incidência de gols em contra-ataques diretos e indiretos no futsal.

Relembrando que não foram computados contra-ataques que terminaram com desarmes do adversário, a divisão proposta por $\operatorname{Voser}^{2}$ em contra-ataques diretos e indiretos não demonstra diferença significativa na incidência de gols. Isso demonstra que, mesmo com a troca de passes Conexões: revista da Faculdade de Educação Física da UNICAMP, Campinas, v. 8, n. 3, p. 16-22, set./dez. 2010. ISSN: 1983-9030 
antes da finalização ou não, o contra-ataque tem praticamente a mesma eficiência na conversão de gols.

A correlação entre a incidência de gols nos contra-ataques diretos e indiretos é forte $(r=0,999)$, demonstrando que independe do tipo de contra-ataque para que a jogada termine em finalização.

É possível perceber que o contra-ataque indireto proporciona maior risco de gols, pois a troca de passes muitas vezes deixa o atleta em uma zona privilegiada tecnicamente e com uma área livre no gol adversário maior, porém, no presente estudo não houve interferência na realização dos gols, uma vez que houve baixo aproveitamento das equipes.

Outros estudos também observaram a incidência de gols resultantes de contra-ataques no futsal. Bello Junior ${ }^{5}$ analisou 21 jogos do Campeonato Paulista e afirmou que, de um total de 121 gols, $73(60,33 \%)$ originaram-se de jogadas de contra-ataque, mostrando melhor aproveitamento em relação ao presente estudo. Já Silva et al. ${ }^{6}$ analisaram 4 jogos da Seleção Brasileira de Novos num torneio internacional e verificaram que de um total de 33 contra-ataques, 7 gols foram convertidos, sendo a efetividade de $21,21 \%$, sendo verificado menor aproveitamento do que o presente estudo.

\section{CONCLUSÃO}

Conclui-se que o contra-ataque é uma das maiores ferramentas técnico/táticas do futsal jogado atualmente, porém que ainda não é bem aproveitada na conversão em gols, pois apenas 10,5\% dos contra-ataques aplicados nas partidas terminam em gol, sendo um aproveitamento baixo na incidência de gols. O baixo aproveitamento é visível em ambos os tipos de contra-ataques, tanto nos diretos quanto nos indiretos, com um grande número de finalizações erradas. Mesmo com esse aproveitamento, o contra-ataque é expressivo e com uma boa representação na quantidade de gols das partidas, onde representa $34,1 \%$ do total de gols marcados, concluindo que os contra-ataques são fatores decisivos nos resultados das partidas, pois é responsável por grande parte dos gols marcados.

Essa ferramenta deve receber mais atenção do que já lhe é concedida, pois necessita ser aprimorada assim como os seus métodos de treinamentos a fim de otimizar a sua eficiência na 
incidência de gols. Deve-se utilizar um olhar atento às finalizações, pois as jogadas de contraataque são muito freqüentes.

Há expectativa de que este estudo venha causar a valorização do contra-ataque, lembrando que a maioria dos gols marcados em partidas do futsal acontece na zona mais próxima possível do gol adversário, onde essa ferramenta de contra-atacar traz grande possibilidade de se conquistar vitórias nas partidas e competições, uma vez que estão aqui evidenciadas como fatores altamente decisivos.

\section{REFERÊNCIAS}

${ }^{1}$ GARGANTA, J. O treino da táctica e da técnica nos jogos desportivos à luz do compromisso cognição-acção. In: BARBANTI, V. J. (Org.). Esporte e atividade física: interação entre rendimento e qualidade de vida. São Paulo: Manole, 2002.

${ }^{2}$ VOSER, R. C. Futsal: princípios técnicos e táticos. 2. ed. Canoas: Ulbra, 2003.

${ }^{3}$ FERREIRA, P. Caracterização da finalização em equipas de futsal. 2004. Disponível em: <http://www.futsalportugal.net/monografia.pdf>. Acesso em: 10 nov. 2009.

${ }^{4}$ SANTANA, W. C.; GARCIA, O. B. A incidência do contra-ataque em jogos de futsal de alto rendimento. Pensar a Prática, v. 10, n. 1, 2007.

${ }^{5}$ BELLO JUNIOR, N. A ciência do esporte aplicada ao futsal. Rio de Janeiro: Sprint, 1998.

${ }^{6}$ SILVA, M. et al. Ações ofensivas no futsal: uma comparação entre as situações de jogo organizado, de contra-ataque e de bola parada. Revista Portuguesa de Ciências do Desporto. Porto, v. 4, n. 2, p. 199, 2004. (Suplemento). 